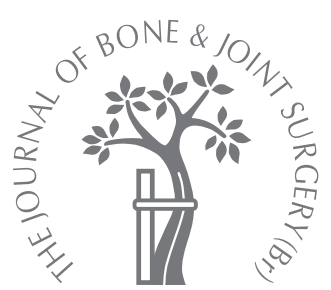

\title{
Acetabular revision with impacted morsellised cancellous bone grafting and a cemented acetabular component
}

\author{
A 20- TO 25-YEAR FOLLOW-UP
}

B. W. Schreurs, J. C. Keurentjes, J. W. M. Gardeniers, N. Verdonschot, T. J. J. H. Slooff, R. P. H. Veth

From the Radboud University Nijmegen Medical Centre, Nijmegen, The Netherlands
B. W. Schreurs, MD, PhD, Orthopaedic Surgeon I. C. Keurentjes, MD, Resident of Orthopaedics I. J. M. Gardeniers, MD, PhD, Orthopaedic Surgeon N N. Verdonschot, PhD Professor of Biomechanics T. J. J. H. Slooff, MD, PhD, Emeritus Professor of Orthopaedics

R. P. H. Veth, MD, PhD, Professor of Orthopaedics Department of Orthopaedics Nijmegen Medical Centre, Radboud University, Intern postcode 357, P. O. Box 9101 6500 HB Nijmegen, The Netherlands.

Correspondence should be sent to Dr B. W. Schreurs; e-mail: b.schreurs@orthop.umcn.n

(C)2009 British Editorial Society of Bone and Joint Surgery doi:10.1302/0301-620X.91B9. $21750 \$ 2.00$

$J$ Bone Joint Surg $[\mathrm{Br}]$ 2009;91-B:1148-53

Received 5 September 2008, Accepted after revision 27 April 2009

\begin{abstract}
We present an update of the clinical and radiological results of 62 consecutive acetabular revisions using impacted morsellised cancellous bone grafts and a cemented acetabular component in 58 patients, at a mean follow-up of 22.2 years (20 to 25). The Kaplan-Meier survivorship for the acetabular component with revision for any reason as the endpoint was $75 \%$ at 20 years ( $95 \%$ confidence interval (CI) 62 to 88 ) when 16 hips were at risk. Excluding two revisions for septic loosening at three and six years, the survivorship at $\mathbf{2 0}$ years was $79 \%$ (95\% Cl 67 to 93 ). With further exclusions of one revision of a well-fixed acetabular component after 12 years during a femoral revision and two after 17 years for wear of the acetabular component, the survivorship for aseptic loosening was $87 \%$ at 20 years $(95 \% \mathrm{Cl}$ 76 to 97). At the final review 14 of the 16 surviving hips had radiographs available. There was one additional case of radiological loosening and four acetabular reconstructions showed progressive radiolucent lines in one or two zones.

Acetabular revision using impacted large morsellised bone chips $10.5 \mathrm{~cm}$ to $1 \mathrm{~cm}$ in diameter) and a cemented acetabular component remains a reliable technique for reconstruction, even when assessed at more than 20 years after surgery.
\end{abstract}

Loss of bone stock is a technically challenging problem in revision total hip replacement (THR). Impaction bone grafting is an attractive biological method of reconstruction since it can restore the lost bone. ${ }^{1,2}$ Previously, we have described the outcome of impaction bone grafting in combination with a cemented acetabular component, with acceptable results at 10 to 15 and 15 to 20 years. ${ }^{3,4}$ However, only continued long-term clinical follow-up can show the true value of the technique. This study provides an update on the outcome of this series of patients at 20 to 25 years.

\section{Patients and Methods}

Between January 1979 and March 1986, 62 acetabular revisions were performed using impacted morsellised bone grafts and a cemented acetabular component in 58 patients with a failed THR. The revisions were performed by four surgeons, although one (TJJHS) operated on half the patients. At the current review, no patient had been lost to follow-up. Revision was undertaken on 44 cemented and six uncemented THRs, nine Wagner double-cup resurfacing replacements and three failed hemiarthroplasties which failed with protrusion of the femoral head into the acetabulum. The original diagnosis had been primary osteoarthritis in 29 hips and secondary osteoarthritis in 29, mainly following childhood hip disorders, and, in four hips, rheumatoid arthritis. The indication for revision was either aseptic (58 hips) or septic loosening (4 hips). Previous revisions had been undertaken in two patients, once and twice, respectively. The group comprised 13 men and 45 women with a mean age at revision of 59.2 years (23 to 82$)$. A total of $37(60 \%)$ procedures were on the left side.

Operative technique. We used the posterolateral approach in all patients, with trochanteric osteotomy in only two. After removal of the component, samples from the tissue interface between the component and bone were sent for frozen section and microscopy to detect possible infection. A two-stage procedure was done in the four hips with known septic loosening and in seven with suspected infection. All debris and interface tissue were carefully removed. Segmental defects in the medial wall of the acetabulum were closed using a slice of corticocancellous bone or a metal mesh. In nine early cases autografts from the iliac crest were used. Later in the series auto- and allografts were combined in 16 hips and allografts alone were used in 37 . In eight of the nine revisions from surface replacement 
arthroplasty bone grafts were taken from the remains of the resected femoral head. All the allografts were fresh-frozen femoral heads from the bone bank, with between one and three used in each case. The grafts were morsellised with a rongeur during the operation to provide cancellous chips with a diameter of $0.5 \mathrm{~cm}$ to $1.0 \mathrm{~cm}$. These chips were then impacted with trial acetabular components, but the trial prosthesis used was at least $2 \mathrm{~mm}$ oversized for the proposed definitive diameter of the implant to create a cement mantle of sufficient thickness. The original centre of rotation of the hip was reconstructed by impaction at the level of the transverse ligament. In 54 hips in this long-term study the graft was covered with a thin vitallium wire mesh. This mesh was placed on the top of the bone graft to limit the direct contact between bone cement and bone, since at that time it was considered to be potentially harmful for bone incorporation. ${ }^{5}$ Subsequently, we realised that the mesh did not add any stability to the reconstruction and that there were no signs of harm being caused by direct contact between the graft and cement. Accordingly, the use of a mesh was discontinued. Cement was pressurised on top of the reconstruction using a seal. In all cases either a $32 \mathrm{~mm}$ polyethylene Müller or Allopro acetabular component (Sulzer, Winterthür, Switzerland) was introduced using antibiotic-loaded bone cement (Palacos with gentamicin; Merck, Darmstadt, Germany). Passive movement of the operated hip was started at 24 hours, and partial weightbearing allowed at six weeks and full weight-bearing after three months.

Clinical and radiological review. At review in July 2006, the series was updated with a minimum follow-up of 20 years since the revision. In all, 41 patients (46 hips) had died or had been revised within 20 years of THR. None of the deaths was related to the hip surgery. Nearly all the patients had been followed annually in detail. In addition to the previous update, we were also able to trace the last patient who had been lost in the previous review and include her result in this update, making the follow-up of the original population complete. Of the surviving 16 revision THRs, ten hips (ten patients) were assessed clinically at our department at a minimum follow-up of 20 years. A total of four patients was interviewed by telephone and one (two hips) was reviewed by an orthopaedic surgeon in another clinic. The Harris hip score ${ }^{6}$ (HHS) and a visual analogue scale (VAS) of satisfaction ( 0 , not satisfied at all; 100 , complete satisfaction) were used for clinical evaluation.

Radiological follow-up was complete in 45 hips, incomplete in 15 and missing in two. Of those examined clinically at a minimum of 20 years after the initial surgery, complete radiological data were available in 14. Anteroposterior views of the pelvis were assessed by two authors (BWS, JCK) whose opinion was reached by consensus. Acetabular defects were assessed by comparing the pre-operative and the first post-operative radiographs and the operation record according to the American Academy of Orthopaedic Surgeons classification. ${ }^{7}$ There were 39 cavitary and
23 combined cavitary and segmental defects (10 central and 13 peripheral). The radiographs at the latest review were compared with those taken after operation, and at follow-up after one, five, ten, 15, 20 and 25 years, if appropriate. Radiolucent lines, defined as lines greater than $2 \mathrm{~mm}$ in width, were scored in the three zones of DeLee and Charnley. ${ }^{8}$ Migration of the acetabular component was estimated in relation to the line between the teardrops. ${ }^{9}$

Statistical analysis. Clinical failure was defined as any need for further revision of the acetabular component. Radiological failure was defined as migration of more than $5 \mathrm{~mm}$ in any direction, or progressive radiolucent lines in all three zones on conventional radiographs. For statistical analysis we used Kaplan-Meier survivorship analysis with the $95 \%$ confidence interval (CI).

\section{Results}

Clinical. The mean HHS of the 15 patients with 16 acetabular reconstructions who were still alive at a mean of 22.2 years (20 to 25 ) was 80 (49 to 98 ). The mean VAS of satisfaction was 90 (70 to 100$)$.

Of the original group of 62 hips, 13 had been revised further (Table I). Two were revised for culture-proven, septic loosening at three and six years after surgery, and eight for aseptic loosening, at six, nine, 11, 12, 13, 14, 21 and 21 years after revision. One well-fixed acetabular component was changed at 12 years in the course of femoral revision for aseptic loosening. Two acetabular components were revised again after 17 years because of wear even though they were well fixed.

Radiological. Most hips had a stable radiological appearance with uniform radiodensity of both graft and host bone, even after follow-up for 20 years (Figs 1 and 2). In one hip, the acetabular component had migrated by $13 \mathrm{~mm}$ soon after the operation, but then remained in that position, and was not recorded as a radiological failure. A normal trabecular structure around the acetabular components was seen in most cases within a year. In ten of the 13 hips which had been revised for septic or aseptic loosening, radiological signs of loosening were present in all zones. In all, four other hips showed radiological loosening at 7, 11, 13 and 22 years after surgery, but were not revised because of the presence of only mild symptoms. Three of these patients died subsequently at 7,13 and 14 years after surgery. One of the 14 hips for which the radiological data were available at a minimum of 20 years had a wellfunctioning THR, but showed radiological loosening. In all, nine of the other 13 hips appeared to be stable radiologically. Of the other four hips one had a progressive radiolucent line in zone I, one a progressive line in zone III, one a progressive line in zones I and III and one a progressive line in zones II and III.

Complications and re-operations. Post-operative complications included two dislocations, which were treated conservatively. Two patients were treated for superficial wound problems and a suspicion of infection. In one hip 
Table I. Details of the 62 consecutive acetabular revisions

\begin{tabular}{|c|c|c|c|}
\hline & Acetabular revisions & & Patients \\
\hline Total studied between 1979 and 1986 & 62 & & 58 \\
\hline Number lost to follow-up & 0 & & 0 \\
\hline Number who died without further surgery & 33 & & 30 \\
\hline Re-revision (hips) & 13 & & 12 \\
\hline For septic loosening of the (hips) & \multirow{4}{*}{\multicolumn{3}{|c|}{$\begin{array}{ll}2 & \text { (at } 3 \text { and } 6 \text { years) } \\
8 & \text { (between } 6 \text { and } 21 \text { years) } \\
1 & \text { (at } 12 \text { years) } \\
2 & \text { (both at } 17 \text { years) }\end{array}$}} \\
\hline For aseptic loosening & & & \\
\hline For mismatch during femoral revision & & & \\
\hline For wear & & & \\
\hline Radiological loosening during follow-up which was not revised & \multicolumn{3}{|c|}{$\begin{array}{l}4 \text { ( } 3 \text { patients died at } 7,11 \text { and } 13 \text { years after surgery and one was } \\
\text { still alive at } 22 \text { years with minor symptoms) }\end{array}$} \\
\hline $\begin{array}{l}\text { Survival rate at } 20 \text { years with the endpoint re-revision for } \\
\text { any reason }\end{array}$ & \multicolumn{3}{|l|}{$75 \%(95 \% \mathrm{Cl} 62$ to 88$)$} \\
\hline $\begin{array}{l}\text { Survival rate at } 20 \text { years, excluding two cases of septic } \\
\text { loosening }\end{array}$ & \multicolumn{3}{|l|}{$79 \%(95 \% \mathrm{Cl} 67$ to 93$)$} \\
\hline $\begin{array}{l}\text { Survival rate at } 20 \text { years with the endpoint re-revision for } \\
\text { aseptic loosening }\end{array}$ & \multicolumn{3}{|l|}{$87 \%(95 \% \mathrm{Cl} 76$ to 97$)$} \\
\hline
\end{tabular}

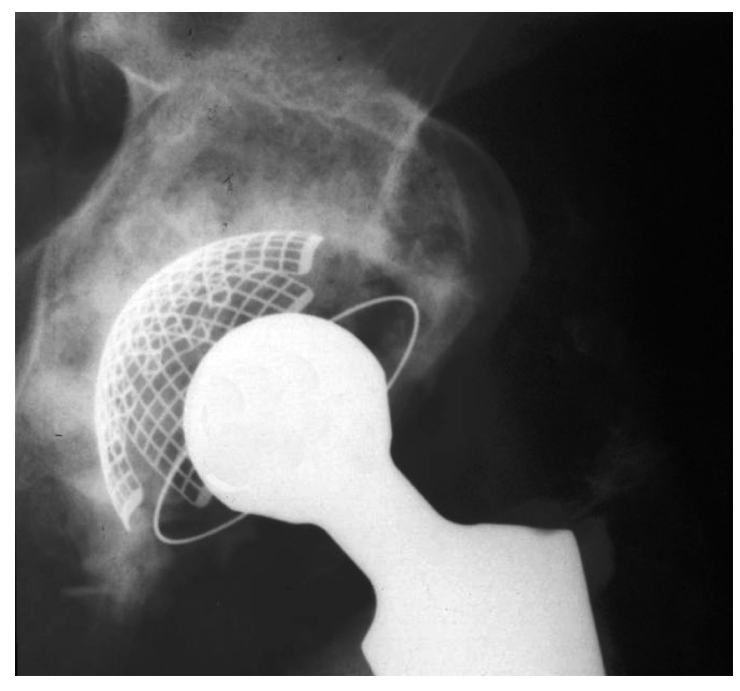

Fig. 1a

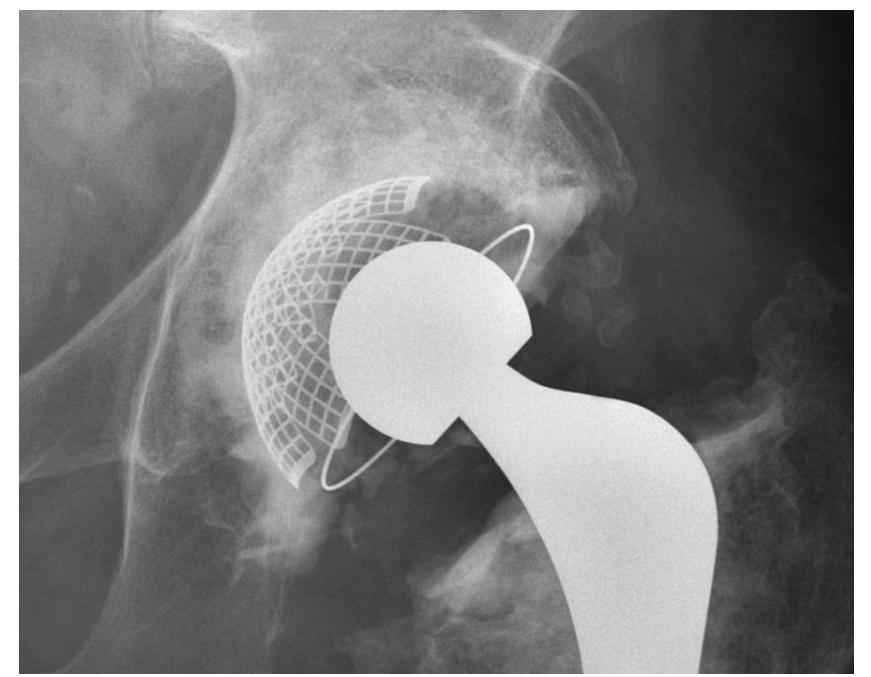

Fig. 1b

Radiograph showing a) a cemented total hip replacement inserted for secondary osteoarthritis after an acetabular fracture. Nine years later the acetabular component was revised with acetabular impaction bone grafting. Two femoral heads were used. A metal mesh was placed on top of the bone graft (a technique no longer used), and b) at review 24 years later showing no signs of acetabular loosening. The acetabular component is stable with radiological incorporation. During this 24 -year follow-up, this patient had two femoral revisions.

heterotopic ossification was excised and one had an exploration of the sciatic nerve for entrapment. Three patients had femoral fractures during follow-up; two of these followed falls and one was caused by a metastasis. In all, four patients had a revision of the femoral component without acetabular revision during the period of study.

Intra-operative findings at re-revision. All hips except one were re-revised in our department. The two hips which failed because of septic loosening were not reconstructed and were converted to permanent excision arthroplasties.
One well-fixed acetabular implant was changed at 12 years in the course of femoral revision for aseptic loosening. After removal of the acetabular component further impaction bone grafting was performed. All nine other hips which failed because of aseptic loosening or wear also underwent re-revision. A new reconstruction was possible in all and bone grafting was repeated. All ten hips had a type-III combined cavitary and segmental defect. In most cases the impression at re-revision was that the original bone graft had been incorporated, but a new acetabular defect, 


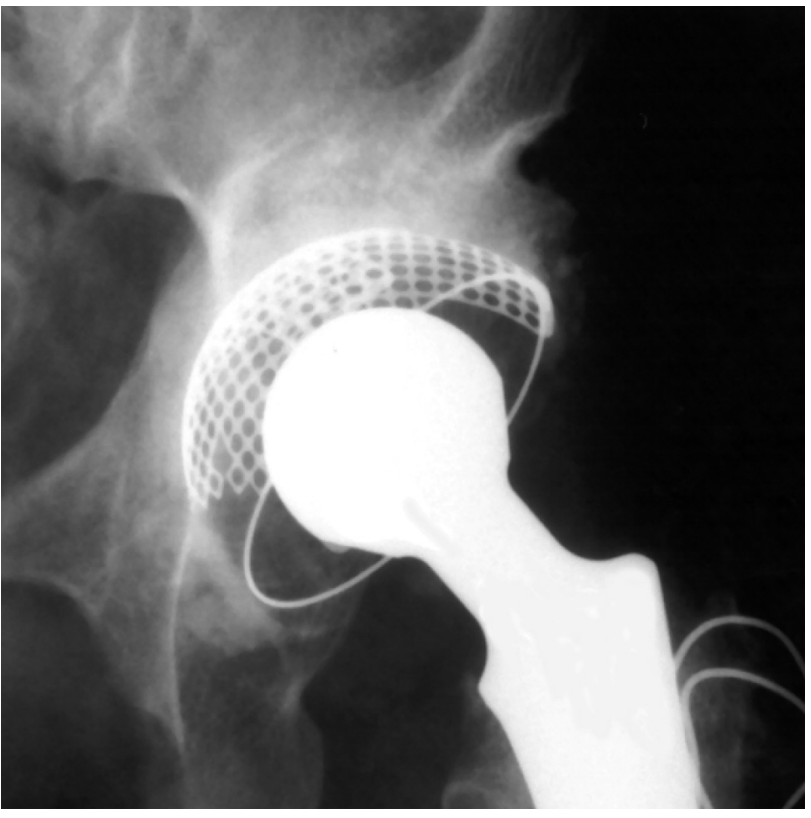

Fig. 2a

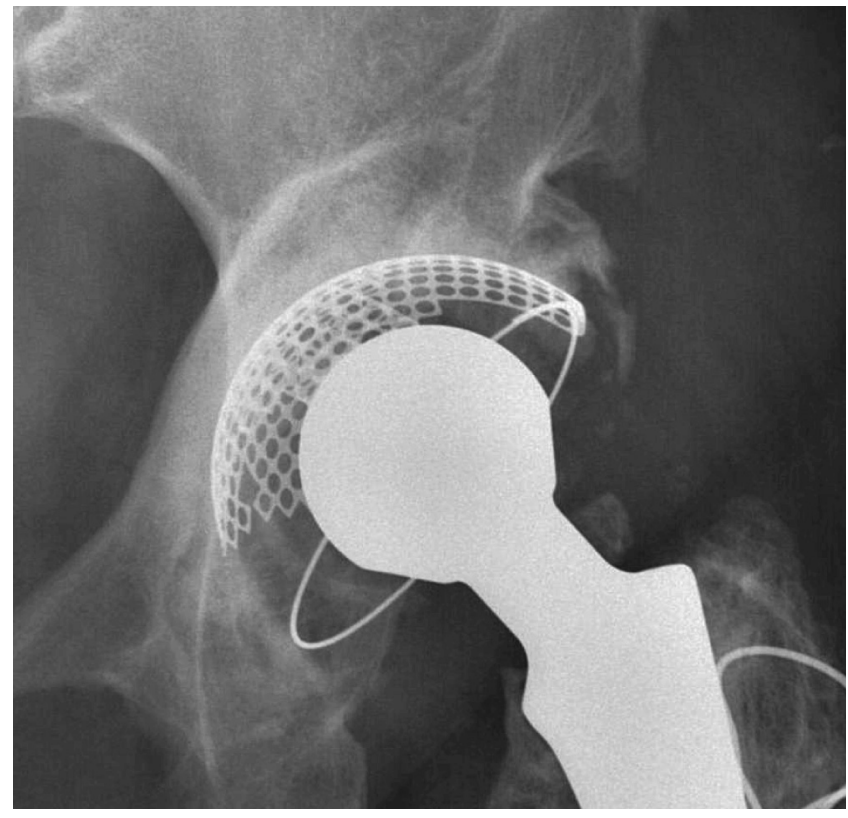

Fig. 2b

Radiograph a) four months after revision of a failed resurfacing hip prosthesis with impaction bone grafting and a cemented acetabular component in a 21-year-old woman. Again, a metal mesh was used on top of the bone graft, and b) 25 years after the reconstruction showing the position of the acetabular component to be unchanged. There is progressive osteolysis in zone I, but overall, the component is well fixed.

according to the AAOS classification, ${ }^{7}$ had occurred because of aseptic loosening. In six hips, one femoral head was used to fill this defect. In three, two heads and in one three heads were necessary. The hip which had a re-revision in another hospital was revised with a Müller reconstructive ring, but further information was unavailable.

Survivorship analysis. The Kaplan-Meier survival analysis of the acetabular component at ten years with revision for any reason was 93\% (95\% CI 86 to 100) and for aseptic loosening was $96 \%$ (95\% CI 91 to 100). At 15 years, these data were respectively, 79\% (95\% CI 67 to 91 ) and $84 \%$ (95\% CI 73 to 95$)$. This current update showed that at 20 years the survival was, respectively, $75 \%(95 \%$ CI 62 to 88$)$ and $79 \%$ (95\% CI 67 to 93 ) with 16 hips at risk. If we also exclude one further revision of a well-fixed acetabular component after 12 years in the course of a femoral revision and two further revisions after 17 years for wear, the survivorship for aseptic loosening was $87 \%$ at 20 years $(95 \%$ CI 76 to 97) (Fig. 3, Table I).

\section{Discussion}

Although there are several options, we strongly believe that bony defects encountered during acetabular revision surgery should be reconstructed biologically if possible. Using impaction bone grafting and cement the bone loss can be reconstructed and the normal biomechanics can be restored using a relatively inexpensive standard implant.

Although our study is an update of previous reports of the same series, ${ }^{3,4}$ we believe that our findings are relevant as this is the longest outcome study available after a revision of a failed THR following patients up to 25 years after the reconstruction. The clinical outcome of all patients has been reported producing a loss-to-follow-up quotient of zero, which according to Murray, Britton and Bulstrode,${ }^{10}$ is ideal. A disadvantage of these long-term studies is the increasing age of the patients. Complete radiological follow-up was available in 14 patients and clinical review by us in only ten, principally due to the physical and mental limitations of this elderly group which prevented them attending for review. Nevertheless, all living patients were contacted and information gathered by telephone.

We believe that our study shows that the survival of these reconstructions with impaction bone grafting and a cemented acetabular component is satisfactory 20 to 25 years after the surgery. The extended review has shown a deterioration in the results because of wear and aseptic loosening with recurrent loss of bone. However, further revision for aseptic loosening or wear could be repeated using the same technique.

The radiological interpretation of incorporation of the graft remains difficult, despite the criteria defined by Conn et al. ${ }^{11}$ Incorporation can only be proven histologically. The process of incorporation has been studied extensively in animal experiments using impaction bone grafting and a cemented acetabular component. ${ }^{12,13}$ Histological analyses in patients is difficult, but in a study based on 24 human acetabular biopsies taken between one month and 15 years after reconstruction, revascularisation and incorporation of the bone graft were generally seen. ${ }^{2}$ Most cases showed lamellar bone with few graft remnants. These biopsies also showed that it 
is important to remove all cartilage from the femoral head before creating the bone chips since cartilage particles were mainly seen in those hips which had been reconstructed by bone grafts obtained from milled femoral heads. Not only will these remnants of cartilage never incorporate into normal trabecular bone, but they also impair the initial stability of the construct. ${ }^{14}$ In a human retrieval, Heekin et al ${ }^{1}$ reported complete incorporation of morsellised allograft on the acetabular side.

The favourable outcome of impaction bone grafting in acetabular revision surgery has also been confirmed by studies from independent centres. ${ }^{15-17}$ However, van Haaren et al ${ }^{18}$ recently reported disappointing results using impaction bone grafting in cemented acetabular revision. The survival rate for aseptic loosening was $72 \%(95 \%$ CI 54 to 81$)$ after a mean follow-up of 7.2 years (1.6 to 9.7). These results are in contrast with other revision series. ${ }^{4,15-17}$ The authors attributed the high rate of failure to the severity of the bone loss in their patients, but, there was no statistically significant difference in the American Academy of Orthopaedic Surgeons classification when comparing their failed with their successful cases $(p=0.3)$. Other factors must play a role. A possible explanation may be the use of very small milled chips. Unfortunately, van Haaren et $\mathrm{al}^{18}$ did not report their mechanism of failure. The outcome of impaction bone grafting will be less favourable in larger defects and its limitations still have to be defined. A recent study has shown that metal mesh, impaction grafting and a cemented acetabular component can be considered for reconstruction of uncontained acetabular defects of medium severity, but not for severe combined deficiencies. ${ }^{19}$

During 30 years of clinical practice some modifications to our technique have been made. The principal change is that metal meshes on top of the graft are no longer used. Initially, there was debate on the potential harm of bone cement on the incorporation of the bone graft. ${ }^{5}$ The mesh was used in order to limit cement-bone contact. Additionally, during that period metal-backed acetabular components were popular. The use of a metal mesh mimicked a metal-backed component. Subsequently, it was appreciated that a metal mesh on top of the bone graft was useless from a mechanical perspective and it became evident that bone cement did not harm the incorporation of the graft. However, we continued to use metal meshes to close defects of the medial and superolateral walls in order to convert combined defects into cavitary defects to facilitate impaction bone grafting. Using these meshes, patients can mobilise earlier. The patients in our study all had a period of bedrest for six weeks. Nowadays, most patients are mobilised on the second day after surgery using crutches for three months. In our study the bone grafts were made by hand from the femoral head using a rongeur. This produced pure cancellous chips with a diameter of $0.5 \mathrm{~cm}$ to $1 \mathrm{~cm}$, but it is a time-consuming exercise making the use of a bone mill attractive. However, most commercial bone mills produce

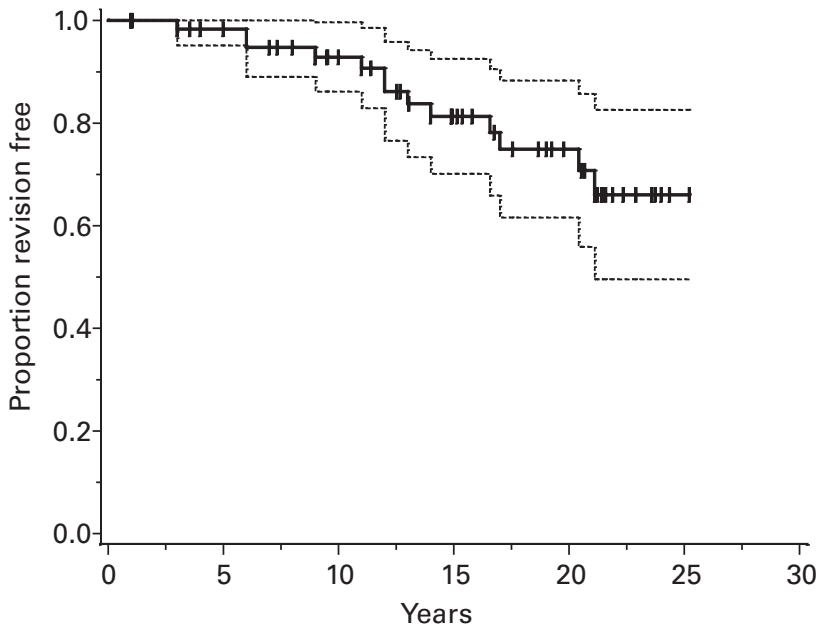

Fig. 3a

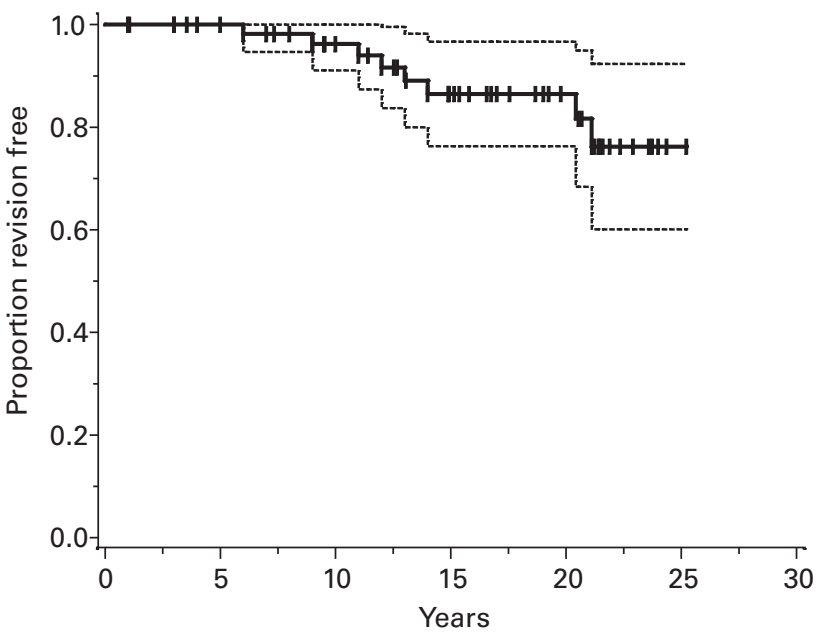

Fig. 3b

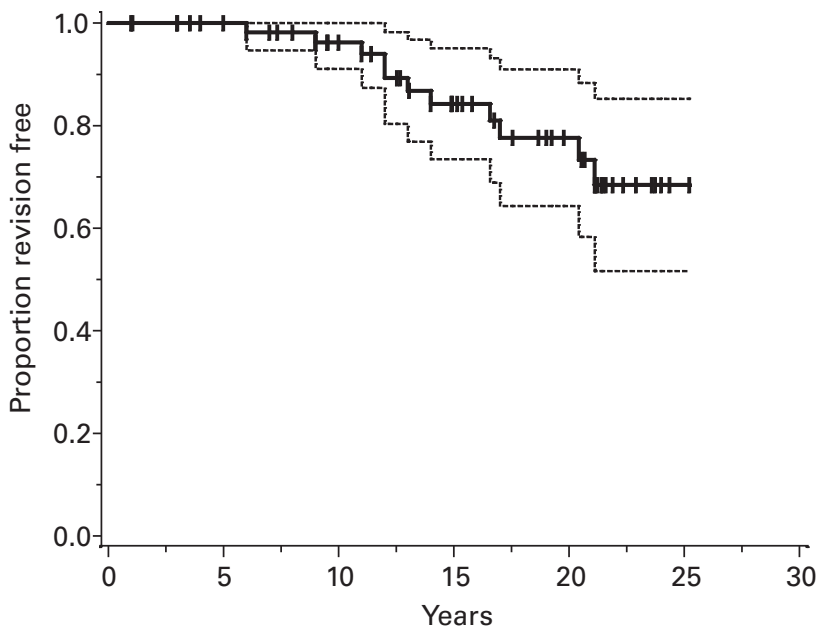

Fig. 3c

Kaplan-Meier curves with the $95 \%$ confidence intervals showing a) revision for any reason as the endpoint, b) excluding two cases of septic loosening and c) with revision for aseptic loosening as the endpoint. 
small chips of $2 \mathrm{~mm}$ to $4 \mathrm{~mm}$ in size. It has been shown experimentally that acetabular reconstruction with smaller bone chips is less stable. ${ }^{20-22}$ We still prefer to use larger chips for acetabular revision which are produced by hand using a rongeur or by using a specially designed bone mill which gives larger chips. Although it was not our practice to wash the bone chips, there is evidence that rinsing can improve the stability of the acetabular component and facilitate incorporation. ${ }^{20,22-24}$

We believe that replenishing the bone stock is the optimal technique in acetabular revisions with impaction bone grafting. The method is reliable with excellent clinical results at over 20 years.

We wish to thank J. Hendriks, for his advice on statistical matters and S. Bolder and A. Asrian for their assistance in this update.

Although none of the authors has received or will receive benefits for personal or professional use from a commercial party related directly or indirectly to the subject of this article, benefits have been or will be received but will be directed solely to a research fund, foundation, educational institution or other nonprofit organisation with which one or more of the authors are associated.

\section{References}

1. Heekin RD, Engh CA, Vinh T. Morselized allograft in acetabular reconstruction: a postmortem retrieval analysis. Clin Orthop 1995;319:184-90.

2. Donk van der S, Buma P, Slooff TJ, Gardeniers JW, Schreurs BW. Incorporation of morselized bone grafts: a study of 24 acetabular biopsy specimens. Clin Orthop 2002;396:131-41.

3. Schreurs BW, Slooff TJ, Buma P, Gardeniers JW, Huiskes R. Acetabular reconstruction with impacted morsellised cancellous bone graft and cement: a 10- to 15 year follow-up of 60 revision arthroplasties. J Bone Joint Surg [Br] 1998;80-B:391-5.

4. Schreurs BW, Bolder SB, Gardeniers JW, et al. Acetabular revision with impacted morsellised cancellous bone grafting and a cemented cup: a 15- to 20 -year follow-up. J Bone Joint Surg [Br] 2004;86-B:492-7.

5. Jones LC, Hungerford DS. Cement disease. Clin Orthop 1987;225:192-206

6. Harris WH. Traumatic arthritis of the hip after dislocation and acetabular fractures: treatment by mold arthroplasty: an end-result study using a new method of result evaluation. J Bone Joint Surg [Am] 1969;51:737-55

7. D'Antonio JA, Capello WN, Borden LS, et al. Classification and management of acetabular abnormalities in total hip arthroplasty. Clin Orthop 1989;243:126-37.

8. DeLee JG, Charnley J. Radiological demarcation of cemented sockets in total hip replacement. Clin Orthop 1976;121:20-32.
9. Garbuz D, Morsi E, Mohamed N, Gross AE. Classification and reconstruction in revision acetabular arthroplasty with bone stock deficiency. Clin Orthop 1996;324:98107

10. Murray DW, Britton AR, Bulstrode CJ. Loss to follow-up matters. J Bone Joint Surg [Br] 1997;79-B:254-7.

11. Conn RA, Peterson LFA, Stauffer RN, Ilstrup D. Management of acetabular deficiency: long-term results of bone grafting the acetabulum in total hip arthroplasty. Orthop Trans 1985;9:451-52.

12. Schimmel JW, Buma P, Versleyen D, Huiskes R, Slooff TJ. Acetabular reconstruction with impacted morselized cancellous allografts in cemented hip arthroplasty: a histological and biomechanical study on the goat. J Arthroplasty 1998;13:438-48

13. Buma P, Arts JJ, Gardeniers JW, Verdonschot N, Schreurs BW. No effect of bone morphogenetic protein-7 (OP-1) on the incorporation of impacted bone grafts in a realistic acetabular model. J Biomed Mater Res B Appl Biomater 2008;84:231-9.

14. Bavadekar A, Cornu O, Godts B, et al. Stiffness and compactness of morselized grafts during impaction: an in vitro study with human femoral heads. Acta Orthop Scand 2001;72:470-6.

15. Comba F, Buttaro M, Pusso R, Piccaluga F. Acetabular reconstruction with impacted bone allografts and cemented acetabular components: a 2- to 13-year follow-up study of 142 aseptic revisions. J Bone Joint Surg [Br] 2006;88-B:865-9.

16. Garcia-Cimbrelo E, Cordero J. Impacted morsellised allograft and cemented cup in acetabular revision surgery: a five to nine year follow-up study. Hip Int 2002:12:281-8.

17. Buckley SC, Stockley I, Hamer AJ, Kerry RM. Irradiated allograft bone for acetabular revision surgery: results at a mean of five years. J Bone Joint Surg [Br] 2005;87-B:310-13

18. van Haaren EH, Heyligers IC, Alexander FG, Wuisman PI. High rate of failure of impaction grafting in large acetabular defects. J Bone Joint Surg [Br] 2007;89-B:296300.

19. Buttaro MA, Comba F, Pusso R, Piccaluga F. Acetabular revision with metal mesh, impaction bone grafting, and a cemented cup. Clin Orthop 2008;466:2482-90.

20. UIImark G. Bigger size and defatting of bone chips will increase cup stability. Arch Orthop Trauma Surg 2000;120:445-7.

21. Bolder SBT, Schreurs BW, Verdonschot N, et al. Bone graft particle size and method of impaction influence initial stability of cemented cups in bone impaction grafting. Acta Orthop Scand 2003;74:652-7.

22. Dunlop DG, Brewster NT, Madabhushi SP, et al. Techniques to improve the shear strength of impacted bone graft: the effect of particle size and washing of the graft. J Bone Joint Surg [Am] 2003;85-A:639-46.

23. Arts JJ, Verdonschot N, Buma P, Schreurs BW. Larger bone graft size and washing of bone grafts prior to impaction enhances the initial stability of cemented cups: experiments using a synthetic acetabular model. Acta Orthop 2006;77:227-33.

24. van der Donk S, Weernink T, Buma $\mathbf{P}$, et al. Rinsing morselized allografts improves bone and tissue ingrowth. Clin Orthop 2003;408:302-10. 